\title{
Existence of integrable solutions for integro-differential in- clusions of fractional order; coupled system approach
}

\author{
A. M. A. El-Sayed ${ }^{a}$, Sh. M. Al-Issa ${ }^{b, c, *}$ \\ ${ }^{a}$ Faculty of Science, Alexandria University, Alexandria, Egypt. \\ ${ }^{b}$ Faculty of Science, Lebanes International University, Beirut, Lebanon. \\ ${ }^{c}$ Faculty of Science, The International University of Beirut, Saida, Lebanon.
}

\begin{abstract}
In this article, we establish the existence of solutions for a functional integral equation of fractional order. The study upholds the case when the set-valued function has $\mathrm{L}^{1}$-Carathèodory selections, we reformulate the functional integral inclusion according to these selections via a classical fixed point theorem of Schauder and present theorem for the existence of integrable solutions. As an application, the existence of solutions of nonlinear functional integro-differential inclusion with an initial value, and the initial value problem for the arbitrary-order differential inclusion will be studied.
\end{abstract}

Keywords: Fractional calculus, integro-differential inclusion, $\mathrm{L}^{1}$-Carathèodory selections, Schauder fixed point principle, Kolmogorov compactness criterion.

2010 MSC: 26A33, 47H30, 47G10.

(C)2020 All rights reserved.

\section{Introduction}

The topic of differential and integral inclusions is of much interest in the subject of set-valued analysis. Differential equations and control processes, the existence theorems for the inclusions problems are generally obtained under the assumption that the set-valued function is either lower or upper semicontinuous on the domain of its definitions $($ see $[2,21])$ and for the discontinuity of the set-valued function (see [8]).

Indeed set-valued functional equations have been extensively investigated by a number of authors and there are many interesting results concerning this problem (see [1, 10-15, 18]).

In this paper we discuss the existence of integrable solutions to the following fractional order functional integral inclusion

$$
x(t) \in F_{1}\left(t, I^{\alpha} f_{2}(t, x(t))\right), \quad \in[0, T],
$$

where $\alpha \in(0,1)$ and $F_{1}:[0, T] \times R^{+} \rightarrow P(R)$ is a set-valued mapping and $P(R)$ denotes the family of nonempty subsets of $R$ under a set of several suitable assumptions on the function $F_{1}$.

\footnotetext{
${ }^{*}$ Corresponding author

Email addresses: amasayed@alexu.edu.eg (A. M. A. El-Sayed), shorouk.alissa@liu.edu.lb (Sh. M. Al-Issa)

doi: $10.22436 /$ jnsa.013.04.02
}

Received: 2019-08-26 Revised: 2019-10-31 Accepted: 2019-11-27 
Our study is based on the selections of the set-valued function $F_{1}$ by reformulating the functional integral inclusion (1.1) into a coupled system. We present the existence of integrable solution under the assumption that a set-valued function $\mathrm{F}_{1}$ has $\mathrm{L}^{1}$-Carathèodory selection and with the classical Schauder fixed point principle and Kolmogorov compactness criterion.

As an application we study the existence of solutions of integro- differential inclusion of fractional order

$$
x(t) \in \int_{0}^{t} F_{1}\left(s, I^{\alpha} f_{2}\left(s, x^{\prime}(s)\right)\right) d s, t \in[0, T], \quad \text { with } x(0)=x_{\circ} .
$$

Also, the initial-value problem for the arbitrary (fractional) order differential inclusion

$$
\frac{d x(t)}{d t} \in F_{1}\left(t, D^{\beta} x(t)\right), \text { a.e. } t \in(0, T], \quad \beta \in(0,1], \quad x(0)=x_{\circ},
$$

where $F_{1}(t, x(t)) L^{1}$-Carathèodory set-valued function defined on $(0, T] \times R^{+}$will be studied.

\section{Preliminaries}

In this section, we introduce notations, definitions and preliminary facts from set-valued analysis which are used throughout this paper. Denote by $\mathrm{L}^{1}(\mathrm{I})$ the class of Lebesgue integrable functions on the interval $\mathrm{I}=[0, \mathrm{~T}]$, endowed with the usual norm

$$
\|x\|=\int_{0}^{T}|x(t)| d t
$$

Definition 2.1. The Riemann-Liouville of a fractional integral of the function $f \in L^{1}(I)$ of order $\alpha \in R^{+}$is defined by

$$
I_{a}^{\alpha} f(t)=\int_{a}^{t} \frac{(t-s)^{\alpha-1}}{\Gamma(\alpha)} f(s) d s
$$

and when $a=0$, we have $I^{\alpha} f(t)=I_{0}^{\alpha} f(t)$.

Definition 2.2. The (Caputo) fractional-order derivative $\mathrm{D}^{\alpha}, \alpha \in(0,1]$ of the absolutely continuous function $\mathrm{g}$ is defined as

$$
D_{a}^{\alpha} g(t)=I_{a}^{1-\alpha} \frac{d}{d t} g(t)=\int_{0}^{t} \frac{(t-s)^{-\alpha}}{\Gamma(1-\alpha)} \frac{d}{d s} g(s) d s, \quad t \in[a, b] .
$$

For further properties of fractional calculus operator see [20, 22-24].

Definition 2.3. Let $X$ and $Y$ be two nonempty sets, a set-valued (multi-valued) map $F: X \rightarrow Y$ is a function that associates to any element $x \in X$ a subset $F(x)$ of $Y$, called the (image) valued of $F$ at $x$.

Definition 2.4. Let $F$ be a strict set-valued map (we say $F$ is strict if the domain of $F$ is $X$ itself ), $f$ is called a selection of $F$ if $f(x) \in F(x)$, for every $x \in X$, we denote by $S_{F}=\{f: f(x) \in F(x), x \in X\}$ the set of all selections of $F$ (for the properties of the selection of $F$ see $[6,10,17,19]$ ).

Definition 2.5. A single-valued function $f: I \rightarrow R \times R$ is called $L^{1}$-Carathèodory if:

(1) $t \rightarrow f(t, x)$ is measurable in $t \in I$ for all $x \in R$;

(2) $x \rightarrow f(t, x)$ is continuous in $x \in R$ for almost all $t \in I$;

(3) there exists $h \in L^{1}(I)$ such that $|f(t, x)| \leqslant h(t)$ for almost all $t \in I$.

Theorem 2.6 ([7]). Let $\mathrm{F}: \mathrm{I} \times \mathrm{R} \rightarrow \mathrm{P}(\mathrm{R})$ be an $\mathrm{L}^{1}$-Carathèodory multi-function, the set $\mathrm{S}_{1} \mathrm{~F}(., x()$.$) is nonempty$ (i.e., there exists a selector $\mathrm{f}$ of $\mathrm{F}$ which belongs to $\mathrm{L}^{1}(\mathrm{I})$ ). 
Theorem 2.7 ([7], Schauder fixed point theorem). Let $\mathrm{Q}$ be a convex subset of a Banach space X, T: Q $\rightarrow \mathrm{Q}$ be a compact, continuous map. Then $\mathrm{T}$ has at least one fixed point in $\mathrm{Q}$.

Theorem 2.8 ([9], Kolmogorov compactness criterion). Let $\Omega \subseteq \mathrm{L}^{\mathrm{p}}(\mathrm{I}), 1 \leqslant \mathrm{P} \leqslant \infty$. If

(i) $\Omega$ is bounded in $\mathrm{L}^{\mathrm{p}}(\mathrm{I})$; and

(ii) $\mathrm{x}_{\mathrm{h}} \rightarrow \mathrm{x}$ as $\mathrm{h} \rightarrow 0$ uniformly with respect to $\mathrm{x} \in \Omega$,

then $\Omega$ is relatively compact in $\mathrm{L}^{\mathrm{p}}(\mathrm{I})$, where

$$
x_{h}(t)=\frac{1}{h} \int_{0}^{t+h} x(s) d s .
$$

\section{Existence of integrable solutions}

In this section, we present our main result by proving the existence of at least one solution $x \in \mathrm{L}^{1}(\mathrm{I})$ of the functional integral inclusion (1.1) under the following assumptions:

$\left(\mathrm{H}_{1}\right)$ Let $\mathrm{F}_{1}(\mathrm{t}, \mathrm{x}(\mathrm{t})): \mathrm{I} \times \mathrm{R}^{+} \rightarrow 2^{\mathrm{R}^{+}}$satisfy the following assumptions:

(i) the set $F_{1}(t, x)$ is non-empty, closed and convex subset for all $(t, x) \in I \times R^{+}$;

(ii) $F_{1}(t,$.$) is upper semi-continuous in x \in R^{+}$for each $t \in I$;

(iii) $F_{1}(., x)$ is measurable in $t \in I$ for each $x \in R^{+}$;

(iv) there exists an integrable function $h(t) \in L^{1}(I)$, such that $\left|F_{1}(t, x)\right|=\sup \left\{\left|f_{1}\right|: f_{1} \in F_{1}(t, x)\right\} \leqslant$ $h(t)$, for almost al $t \in I$;

$\left(\mathrm{H}_{2}\right) f_{2}: \mathrm{I} \times \mathrm{R}^{+} \rightarrow \mathrm{R}^{+}$, satisfies Carathèodory condition, i.e., $f_{2}$ is measurable in $t$ for any $x \in \mathrm{R}^{+}$and continuous in $x$ for almost all $t \in I$. There exists a function $a \in L^{1}$ and a constant $b>0$ such that

$$
\left|f_{2}(t, x)\right| \leqslant a(t)+b|x|, \quad \forall t \in I \text { and } x \in R^{+} .
$$

Now, let

$$
y(t)=I^{\alpha} f_{2}(t, x(t)), \quad t \in I .
$$

Then the nonlinear functional integral inclusion (1.1) can be written in the form of the coupled system of functional inclusion and functional integral equation

$$
\begin{aligned}
& x(t) \in F_{1}(t, y(t)), \quad t \in I . \\
& y(t)=I^{\alpha} f_{2}(t, x(t)), \quad t \in I .
\end{aligned}
$$

Definition 3.1. Let $X$ be the class of all ordered pairs $(u, v), u, v \in C[0, T]$, with the norm

$$
\|(u ; v)\|_{x}=\|u\|+\|v\| .
$$

Definition 3.2. By a solution of the coupled system (3.1), (3.2) we mean the functions $x, y \in L^{1}(I)$ satisfying (3.1), (3.2).

Now for the existence of integrable solution $U=(x, y), x, y \in L^{1}(I)$ of the coupled system (3.1), (3.2) we have the following theorem.

Theorem 3.3. Let the assumptions $\left(\mathrm{H}_{1}\right)-\left(\mathrm{H}_{2}\right)$ be satisfied. Then there exists at least one integrable solution $\mathrm{U}=$ $(x, y), x, y \in L^{1}(I)$ of the coupled system (3.1), (3.2).

Proof. It is clear that from Theorem 2.6 and assumption $\left(\mathrm{H}_{2}\right)$, the set of $\mathrm{L}^{1}$-Carathèodory selection of $\mathrm{F}_{1}$ is non empty. So, the solution of the single-valued integral equation

$$
x(t)=f_{1}\left(t, I^{\alpha} f_{2}(t, x(t))\right), \quad t \in I,
$$

where $f_{1} \in S_{F_{1}}$, is a solution to the inclusion (1.1). It must be noted that the Carathèodory selection $\mathrm{f}_{1}: \mathrm{I} \times \mathrm{R}^{+} \rightarrow \mathrm{R}^{+}$satisfies the following assumptions: 
(I) $f_{1}(x,$.$) is continuous in x \in R^{+}$for almost all $t \in I$;

(II) $f_{1}(., t)$ is measurable in $t \in I$ for any $x \in R^{+}$;

(III) there exists an integrable function $h(t) \in L^{1}(I)$ such that $\left|f_{1}(t ; x)\right| \leqslant h(t), t \in I$.

Then the nonlinear functional integral equation (3.3) can be written in the form

$$
x(t)=f_{1}(t, y(t)), \quad t \in I .
$$

Hence, the functional integral equation (3.3) is equivalent to the coupled system (3.2) and (3.4). Let

$$
U(t)=(x(t), y(t))=\left(f_{1}(t, y(t)), I^{\alpha} f_{2}(t, x(t))\right), \quad t \in I .
$$

Let $A$ be any operator defined by

$$
A U(t)=A(x(t), y(t))=\left(A_{1} y(t), A_{2} x(t)\right),
$$

where $A_{1} y(t)=f_{1}(t ; y(t)), t \in I, A_{2} x(t)=I^{\alpha} f_{2}(t, x(t)), t \in I$. Let the set $Q_{r}$ be defined as

$$
Q_{r}=\left\{U=(x, y) \in X: x, y \in L^{1}[0, T],\|U\| \leqslant r\right\}, r=\|h\|+\frac{(\|a\|+b\|x\|) T^{\alpha}}{\Gamma(\alpha+1)} .
$$

Then, it is clear that it is a nonempty, bounded, closed, and convex. Let $U \in Q_{r}$ be an arbitrary ordered pair, then

$$
\left|A_{1} y(t)\right|=\left|f_{1}(t ; y(t))\right|, \quad t \in I .
$$

From the properties (1)-(3) of Definition 2.5, and by integration, we get

$$
\int_{0}^{t}\left|A_{1} y(s)\right| d s=\int_{0}^{t}\left|f_{1}(s ; y(s))\right| d s \leqslant \int_{0}^{t}\left|f_{1}(s ; y(s))\right| d s \leqslant \int_{0}^{t} h(s) d s \leqslant \int_{0}^{t}|h(s)| d s .
$$

Then $\left\|A_{1} y\right\| \leqslant\|h\|$ and

$$
\begin{aligned}
\left|A_{2} x(t)\right| & =\left|I^{\alpha} f_{2}(t, x(t))\right| \\
\left\|A_{2} x\right\| & \leqslant \int_{0}^{t}\left|I^{\alpha} f_{2}(s, x(s))\right| d s \\
& \leqslant \int_{0}^{t}\left|\int_{0}^{s} \frac{(s-\tau)^{\alpha-1}}{\Gamma(\alpha)} f_{2}(\tau, x(\tau)) d \tau\right| d s \\
& \leqslant \int_{0}^{t} \int_{0}^{s} \frac{(s-\tau)^{\alpha-1}}{\Gamma(\alpha)}\left|f_{2}(\tau, x(\tau))\right| d \tau d s \\
& \leqslant \int_{0}^{t} \int_{0}^{s} \frac{(s-\tau)^{\alpha-1}}{\Gamma(\alpha)}|a(\tau)| d \tau d s+\int_{0}^{t} \int_{0}^{s} \frac{(s-\tau)^{\alpha-1}}{\Gamma(\alpha)} b|x(\tau)| d \tau d s \\
& \leqslant \int_{0}^{t}|a(\tau)| \int_{\tau}^{t} \frac{(s-\tau)^{\alpha-1}}{\Gamma(\alpha)} \mathrm{d} s \mathrm{~d} \tau+b \int_{0}^{t}|x(\tau)| \int_{\tau}^{t} \frac{(s-\tau)^{\alpha-1}}{\Gamma(\alpha)} \mathrm{d} s \mathrm{~d} \tau \\
& \leqslant \int_{0}^{t}|\mathrm{a}(\tau)| \frac{(t-\tau)^{\alpha}}{\Gamma(\alpha+1)} \mathrm{d} \tau+b \int_{0}^{t}|x(\tau)| \frac{(t-\tau)^{\alpha}}{\Gamma(\alpha+1)} \mathrm{d} \tau \\
& \leqslant \frac{\|\mathrm{a}\| T^{\alpha}}{\Gamma(\alpha+1)}+\frac{\mathrm{b} T^{\alpha}}{\Gamma(\alpha+1)} \int_{0}^{t}|x(\tau)| d \tau \\
& \leqslant \frac{\|a\| T^{\alpha}}{\Gamma(\alpha+1)}+\frac{b\|x\| T^{\alpha}}{\Gamma(\alpha+1)} .
\end{aligned}
$$

Now

$$
\|A u\|_{x}=\left\|A_{1} y\right\|+\left\|A_{2} x\right\| \leqslant\|h\|+\frac{(\|a\|+b\|x\|) T^{\alpha}}{\Gamma(\alpha+1)} .
$$


Hence $A U \in Q_{r}$, which proves that $A Q_{r} \subset Q_{r}$, i.e., $A: Q r \rightarrow Q r$. The estimate shows that the operator $A$ maps $l^{1}(I)$ into itself.

Now, let us observe that the assumptions (I)-(III) imply that $A_{1}$ is continuous on the set $Q_{r}$ (see $[3,5]$ ), and from the assumptions $\left(\mathrm{H}_{3}\right), \mathrm{f}_{2}$ is continuous in $x$ and $\mathrm{I}^{\alpha}$ maps $\mathrm{L}^{1}(\mathrm{I})$ continuously into itself, then $I^{\alpha} f(t, x(t))$ is continuous in $x$, and the operator $A_{2}$ is continuous on the set $Q_{r}$ (see $\left.[4,16]\right)$. Hence, we deduce that the operator $A$ is continuous on $Q_{r}$.

Finally, we will show that $A$ is compact, to prove this we will apply Kolmogorov compactness criterion. Let $\Omega$ be a bounded subset of $Q_{r}$. Then $(A \Omega)$ is bounded in $L^{1}(I)$, i.e, condition (i) of Theorem 2.8 is satisfied.

It remains to show that $(A U)_{h} \rightarrow A U$ in $L^{1}$ as $h \rightarrow 0$ uniformly with respect to $A U \in \Omega$. We have the following.

Let $\mathrm{U} \in \Omega \subset \mathrm{Q}_{\mathrm{r}}$, that is $\mathrm{y}, \mathrm{x} \in \Omega \subset \mathrm{Q}_{\mathrm{r}},\left\{\mathrm{A}_{1} \Omega\right\},\left\{\mathrm{A}_{2} \Omega\right\} \subset \mathrm{Q}_{\mathrm{r}} \subset \mathrm{L}^{1}(\mathrm{I})$, then

and

$$
\left(A_{1} y\right)_{h}(t)-\left(A_{1} y\right)(t)=\frac{1}{h} \int_{t}^{t+h} A_{1} y(\tau) d \tau-A_{1} y(t)=\frac{1}{h} \int_{t}^{t+h}\left(A_{1} y(\tau)-A_{1} y(t)\right) d \tau
$$

$$
\left|\left(A_{1} y\right)_{h}(t)-\left(A_{1} y\right)(t)\right| \leqslant \frac{1}{h} \int_{t}^{t+h}\left|A_{1} y(\tau)-A_{1} y(t)\right| d \tau
$$

then

$$
\begin{aligned}
\left\|\left(A_{1} y\right)_{h}(t)-\left(A_{1} y\right)(t)\right\| & =\int_{0}^{T}\left|\left(A_{1} y\right)_{h}(t)-A_{1} y(t)\right| d t \\
& \leqslant \int_{0}^{T} \frac{1}{h} \int_{t}^{t+h}\left|A_{1} y(\tau)-A_{1} y(t)\right| d \tau d t \\
& \leqslant \int_{0}^{T} \frac{1}{h} \int_{t}^{t+h}|p(\tau)-p(t)| d \tau d t+\int_{0}^{T} \frac{1}{h} \int_{t}^{t+h}\left|f_{1}(\tau, y(\tau))-f_{1}(t, y(t))\right| d \tau d t
\end{aligned}
$$

Now $f_{1} \in L^{1}(I)$, then $([25])$

$$
\frac{1}{h} \int_{t}^{t+h}\left|f_{1}(\tau, y(\tau))-f_{1}(t, y(t))\right| d \tau \rightarrow 0
$$

Therefore $\left(A_{1} y\right)_{h} \rightarrow\left(A_{1} y\right)$, uniformly as $h \rightarrow 0$,

$$
\begin{aligned}
\left\|\left(A_{2} x\right)_{h}(t)-\left(A_{2} x\right)(t)\right\| & =\int_{0}^{T}\left|\left(A_{2} x\right)_{h}(\tau)-A_{2} x(t)\right| d t \\
& \leqslant \int_{0}^{T} \frac{1}{h} \int_{t}^{t+h}\left|A_{2} x(\tau)-A_{2} x(t)\right| d \tau d t \\
& \leqslant \int_{0}^{T} \frac{1}{h} \int_{t}^{t+h}\left|I^{\alpha} f_{2}(\tau, x(\tau))-I^{\alpha} f_{2}(t, x(t))\right| d \tau d t .
\end{aligned}
$$

Now $f_{2} \in L^{1}(I)$ and $I^{\alpha} f_{2} \in L^{1}(I)$, then following ([25]) we have

$$
\frac{1}{h} \int_{t}^{t+h}\left|I^{\alpha} f_{2}(\tau, x(\tau))-I^{\alpha} f_{2}(t, x(t))\right| d \tau d t \rightarrow 0 .
$$

Therefore

$$
\left(A_{2} x\right)_{h} \rightarrow\left(A_{2} x\right), \text { uniformly as } h \rightarrow 0 .
$$

Now

$$
A(x, y)_{h}(t)-A(x, y)(t)=\frac{1}{h} \int_{t}^{t+h} A(x, y)(\tau) d \tau-A(x, y)(t)
$$




$$
\begin{aligned}
& =\frac{1}{h} \int_{t}^{t+h}(A(x, y)(\tau)-A(x, y)(t)) d \tau \\
& =\frac{1}{h} \int_{t}^{t+h}\left(\left(A_{2} x(\tau), A_{1} y(\tau)\right)-\left(A_{2} x(t), A_{1} y(t)\right)\right) d \tau
\end{aligned}
$$

Then

$$
\begin{aligned}
\left\|(A U)_{h}(t)-(A U)(t)\right\| & =\left\|A(x, y)_{h}(t)-A(x, y)(t)\right\| \\
& =\int_{0}^{T}\left|\frac{1}{h} \int_{t}^{t+h}\left(A_{2} x(\tau), A_{1} y(\tau)\right)-\left(A_{2} x(t), A_{1} y(t)\right) d \tau\right| d t \\
& \leqslant \int_{0}^{T} \frac{1}{h} \int_{t}^{t+h}\left|\left(A_{2} x(\tau), A_{1} y(\tau)\right)-\left(A_{2} x(t), A_{1} y(t)\right)\right| d \tau d t \\
& \leqslant \int_{0}^{T} \frac{1}{h} \int_{t}^{t+h}\left|\left(A_{2} x(\tau)-A_{2} x(t)\right),\left(A_{1} y(\tau)-A_{1} y(t)\right)\right| d \tau d t \\
& \leqslant \int_{0}^{T} \frac{1}{h} \int_{t}^{t+h}\left[\left|A_{2} x(\tau)-A_{2} x(t)\right|+\left|A_{1} y(\tau)-A_{1} y(t)\right|\right] d \tau d t \\
& \left.\leqslant \int_{0}^{T} \frac{1}{h} \int_{t}^{t+h}\left|A_{2} x(\tau)-A_{2} x(t)\right| d \tau d t+\int_{0}^{T} \frac{1}{h} \int_{t}^{t+h}\left|A_{1} y(\tau)-A_{1} y(t)\right|\right] d \tau d t \rightarrow 0,
\end{aligned}
$$

since from the above estimate we show that

$$
\left(A_{2} x\right)_{h} \rightarrow\left(A_{2} x\right) \text {, uniformly as } h \rightarrow 0
$$

and

$$
\left(A_{1} y\right)_{h} \rightarrow\left(A_{1} y\right), \text { uniformly as } h \rightarrow 0 .
$$

Hence

$$
(\mathrm{AU})_{\mathrm{h}} \rightarrow(\mathrm{AU}) \text {, uniformly as } \mathrm{h} \rightarrow 0 .
$$

Then, by Theorem 2.8 we deduce that $(A \Omega)$ is relatively compact, that is, $A$ is a compact operator.

According to Schauder fixed point theorem, there exists at least one fixed point $U \in Q_{r}$, and then the system (3.2), (3.4) and consequently the system (3.1), (3.2) has at least one integrable solution $U=(x, y) \in$ $\mathrm{Q}_{r}, x ; y \in \mathrm{L}^{1}(\mathrm{I})$. Hence, there exists at least one integrable solution of the functional integral inclusion (1.1).

\section{Integro-differential inclusion}

As an application of our main result we present the existence of at least one solution $x \in \mathrm{L}^{1}(\mathrm{I})$ of the functional integro-differential inclusion (1.2).

Definition 4.1. By a solution of the problem of integro-differential inclusion (1.2) we mean a function $x \in \mathrm{L}^{1}(\mathrm{I})$ and this function satisfies (1.2).

Theorem 4.2. Let the assumptions of Theorem 3.3 be satisfied, then there exists at least one solution $x \in \mathrm{L}^{1}(\mathrm{I})$ of the integro-differential inclusion (1.2).

Proof. Differentiating both sides of (1.1), we obtain

$$
x^{\prime}(t) \in F_{1}\left(t, I^{\alpha} f_{2}\left(t, x^{\prime}(t)\right)\right),
$$

put $x^{\prime}(t)=u(t) \in L^{1}$, then (1.1) will be similar to (1.2), and

$$
x(t)=x(0)+\int_{0}^{t} u(s) d s \in L^{1}[0, T]
$$

and from Theorem 3.3 there exists at least one solution $x \in \mathrm{L}^{1}(\mathrm{I})$ for the problem (1.2). 


\section{Differential inclusion}

Consider now the initial value problem of the differential inclusion (1.3).

Theorem 5.1. Let the assumptions of Theorem 3.3 be satisfied, then the initial value problem (1.3) has at least one solution $x \in \mathrm{L}^{1}(\mathrm{I})$.

Proof. Let $y(t)=\frac{d x(t)}{d t}$, and $\alpha=\beta-1$, then the inclusion (1.3) will be

$$
y(t) \in F_{1}\left(t, I^{\beta-1} y(t)\right) .
$$

Letting $f_{2}(t, x)=x$ and applying Theorem 3.3 on the functional inclusion (5.1), we deduce that there exists a solution $y \in \mathrm{L}^{1}(\mathrm{I})$ of the functional inclusion (5.1).

This implies that there exists at least one solution $x \in \mathrm{L}^{1}(\mathrm{I})$

$$
x(t)=x_{\circ}+\int_{0}^{t} y(s) d s
$$

of the initial-value problem (1.3). This completes the proof.

\section{References}

[1] S. Al-Issa, A. M. A. El-Sayed, Positive integrable solutions for nonlinear integral and differential inclusions of fractionalorders, Comment. Math., 49 (2009), 171-177. 1

[2] J.-P. Aubin A. Cellina, Differential Inclusion, Springer-Verlag, Berlin, (1984). 1

[3] J. Banaś, On the superposition operator and integrable solutions of some functional equations, Nonlinear Anal., 12 (1988), 777-784. 3

[4] J. Banaś, Integrable solutions of Hammerstein and Urysohn integral equations, J. Austral. Math. Soc. Ser. A, 46 (1989), 61-68. 3

[5] F. E. Browder, W. V. Petryshyn, Construction of fixed points of nonlinear mappings in Hilbert spaces, J. Math. Anal. Appl., 20 (1967), 197-228. 3

[6] A. Cellina, S. Solimini, Continuous extensions of selections, Bull. Polish Acad. Sci. Math., 35 (1989), 573-581. 2.4

[7] K. Deimling, Nonlinear Functional Analysis, Springer-Verlag, Berlin, (1985). 2.6, 2.7

[8] B. C. Dhage, A functional integral inclusion involving discontinuities, Fixed Point Theory, 5 (2004), 53-64. 1

[9] J. Dugundji,, A. Granas, Fixed Point Theory, Państwowe Wydawnictwo Naukowe (PWN), Warsaw, (1982). 2.8

[10] A. M. A. El-Sayed, A.-G. Ibrahim, Multivalued fractional differential equations, Appl. Math. Comput., 68 (1995), 15-25. 1, 2.4

[11] A. M. A. El-Sayed, A.-G. Ibrahim, Set-valued integral equations of fractional-orders, Appl. Math. Comput., 118 (2001), $113-121$.

[12] A. M. A. El-Sayed, S. M. Al-Issa, Monotonic continuous solution for a mixed type integral inclusion of fractional order, J. Math. Appl., 33 (2010), 27-34.

[13] A. M. A. El-Sayed, S. M. Al-Issa, Existence of continuous solutions for nonlinear functional differential and integral inclusions, Malaya J. Mat., 7 (2019), 541-544.

[14] A. M. A. El-Sayed, S. M. Al-Issa, Monotonic integrable solution for a mixed type integral and differential inclusion of fractional orders, Int. J. Differ. Equations Appl., 18 (2019), 10 pages.

[15] A. M. A. El-Sayed, S. M. Al-Issa, Monotonic solutions for a quadratic integral equation of fractional order, AIMS Mathematics, 4 (2019), 821-830. 1

[16] G. Emmanuele, Integrable solutions of Hammerstein integral equations, Appl. Anal., 50 (1993), 277-284. 3

[17] A. Fyszkowski, Continuous selection for a class of non-convex multivalued maps, Studia Math., 76 (1983), 163-174. 2.4

[18] A.-G. Ibrahim, A. M. A. El-Sayed, Definite integral of fractional order for set-valued function, J. Fract. Calc., 11 (1997), 81-87. 1

[19] K. Kuratowski, C. Ryll-Nardzewski, Ageneral theorem on selectors, Bull. Acad. Polon. Sci. Sér. Sci. Math. Astronom. Phys., 13 (1965), 397-403. 2.4

[20] K. S. Miller, B. Ross, An Introduction to the fractional calculus and fractional differential equations, John Wiley \& Sons, New York, (1993). 2.2

[21] D. O'Regan, Integral inclusions of upper semi-continuous or lower semi-continuous type, Proc. Amer. Math. Soc., 124 (1996), 2391-2399. 1

[22] I. Podlubny, Fractional Differential Equations, Academic Press, San Diego, (1999). 2.2

[23] I. Podlubny, A. M. A. EL-Sayed, On two defintions of fractional calculus, Solvak Academy Sci.-Ins. Eyperimental Phys., (1996), 3-96.

[24] S. G. Samko, A. A. Kilbas, O. I. Marichev, Integrals and Derivatives of Fractional Orders and Some of their Applications, Nauka i Teknika, Minsk, (1987). 2.2

[25] C. Swartz, Measure, integration and function spaces, World Scientific Publishing Co., River Edge, (1994). 3 